\title{
Potential Probiotic Lactobacillus Rhamnosus (MTCC-5897) Attenuates Escherichia Coli Induced Inflammatory Response in Intestinal Cells
}

\author{
Taruna Gupta \\ National Dairy Research Institute \\ Harpreet Kaur \\ National Dairy Research Institute \\ Suman Kapila \\ National Dairy Research Institute \\ Rajeev Kapila ( $\nabla$ rkapila69@rediffmail.com ) \\ ICAR-National Dairy Research Institute https://orcid.org/0000-0002-2795-3720
}

\section{Research Article}

Keywords: Probiotic, Intestinal epithelial cells, Cytokines, Immunomodulation, and NF-KB

Posted Date: May 27th, 2021

DOI: https://doi.org/10.21203/rs.3.rs-533546/v1

License: (c) (i) This work is licensed under a Creative Commons Attribution 4.0 International License.

Read Full License 


\section{Abstract}

Probiotics are microbes having tremendous potential to prevent gastrointestinal disorders. In current investigation, immunomodulatory action of probiotic Lactobacillus rhamnosus (LR:MTCC-5897) was studied during exclusion, competition and displacement of Escherichia coli on intestinal epithelial (Caco2) cells. The incubation of intestinal cells with $E$. coli, enhanced downstream signalling and activated nuclear factor kappa B (NF-KB). This significantly increased $(p<0.01)$ the pro-inflammatory cytokines (IL8 , TNF-a and IFN- $Y$ ) expression. While, incubation of epithelial cells with $L$. rhamnosus during exclusion and competition with E. coli, counteracted these enhanced expressions. The immunomodulatory feature of $L$ rhamnosus was also highlighted with increased $(p<0.05)$ transcription of toll like receptor-2 (TLR-2) and single Ig IL-1-related receptor (SIGIRR) along with diminished expression of TLR-4. Likewise, attenuation $(\mathrm{p}<0.05)$ of E.coli-mediated enhanced nuclear translocation of NF-kB p-65 subunit by $L$. rhamnosus during exclusion was confirmed with western blotting. Thus, present finding establishes the prophylactic potential of $L$. rhamnosus against exclusion of E. coli in intestinal cells.

\section{Introduction}

The human gastrointestinal tract (GIT) gets colonized by variety of microbes soon after the birth of neonates. These gut microbes have demonstrated positive impact on human health by modulating metabolic functions including digestion of dietary substances, absorption of nutrients and transformations of xenobiotics. Hence, these commensal organisms are commonly referred as "hidden organ" of the body (Thursby and Juge 2017). Furthermore, intestinal cells, which remain in direct contact with ingested microbes act as the first line of defense against any foreign material entering the gut. The crosstalk between gut microbiota and intestinal epithelial cells cause activation of downstream pathways and play crucial role in the regulation of immune response and the maintenance of barrier integrity (Kawai and Akira 2009). Various factors like diet, stress, unhealthy lifestyle and use of antibiotics adversely disrupt gut microbiota composition (Oriach et al. 2016) to unbalanced state known as dysbiosis, which prompt unregulated induction of local and systemic immune responses (Belkaid and Hand 2014). Unfortunately, these immune-compromised conditions are used by pathobiont or opportunistic pathogens inciting damaging effects in the host through the disruption of epithelial barrier which prompt intestinal disorders like inflammatory bowel diseases (IBD), non-alcoholic fatty liver disease, type I diabetes, obesity and rheumatoid arthritis etc (Lazar et al. 2018). Escherichia coli, a common inhabitant of human gastrointestinal tract, behave as a harmless component of normal gut flora. But, commensal E. colistrains caused number of human maladies like IBD by prompting a dysregulated immune response when host milieu was modified by specific environmental or genetic conditions (Kittana et al. 2018; Bereswill et al. 2013; Kim et al. 2005). Previous evidences displayed that E. coli $\mathrm{K} 12$ which is generally referred as "safe" strain, have some virulence genes and regulatory process similar to pathogenic bacteria and could switch to invasive and pathogenic life style without any major change in genetic flux (Koli et al. 2011). These bacteria further translocated to extra intestinal tissue sites like mesenteric lymph nodes, spleen and liver by disruption of gut barrier in immunocompromised aged 
mice (Sharma et al. 2014). Similarly, under in vitro conditions, E. coli K12 enhanced the intestinal permeability by altering the barrier integrity through decreasing the expression of tight junctions (Bhat et al. 2019, a). Furthermore, E. coli K12 derived lipopolysaccharides (LPS) also caused enhanced T-helper (Th1/Th17) immune response which resulted in severe intestinal inflammation in mice model (Gronbach et al. 2014).

Thus, balancing the deregulated bacterial ecosystem is only a substitute for the prevention of various gutrelated diseases and conferring health benefits. Nowadays, nutritionists and researchers are looking forward to probiotics as a healthier alternative to preserve gut immune homeostasis. Probiotics have been known to have many beneficial effects on metabolism, junctional integrity and regulation of mucosal or systemic immune response (Galdeano et al. 2019; Bron et al. 2017). Therefore, probiotic consumption as a versatile functional food has increased tremendously due to its enormous health effects. Though, the number of indirect evidences depicted the health benefits of probiotics through immune-modulations that displayed changes in expressions of immunoglobulins and pro-inflammatory cytokines in pre-clinical and clinical trials (Oh et al. 2018; Groeger et al. 2013; Milajerdi et al. 2019; Horvath et al. 2016). However, scanty direct evidences are available which can suggest undergoing molecular events to establish microbe's potential individually because probiotic microbes have highly complex and strain specific mode of action (Chiu et al. 2013). Hence, the present study was designed to understand the immunomodulatory signals released from host intestinal epithelial cells, being the first site of interaction after ingestion, in response to probiotic bacteria $L$. rhamnosus in presence of $E$. coli. Earlier, this potential probiotic strain of L. rhamnosus (MTCC:5897) restored Th1/Th2 immune homeostasis, anti-oxidative status and antagonize translocation of pathogenic $E$. coli in aging mice (Sharma et al. 2014). Likewise, its feeding in the form of fermented milk in ovalbumin allergen sensitized weaning mice also alleviated symptoms of allergies and depicted its immunomodulatory potential (Saliganti et al. 2015). This potential probiotic also maintained junctional integrity in $E$. coli induced inflammatory response in intestinal cells (Bhat et al. 2019,a) and found safe during feeding to weanling mice (Bhat et al. 2019,b).

\section{Materials And Methods}

\subsection{Cell line and culture conditions}

The human epithelial colorectal adenocarcinoma cell line (Caco-2) was purchased from NCCS, Pune, Maharashtra (India) and maintained in Dulbecco's Modified Eagle's Medium (DMEM) (Sigma-Aldrich, St. Louis, Missouri, USA) supplemented with 10\% fetal bovine serum (Sigma-Aldrich, St. Louis, Missouri, USA), along with $1 \%$ antibiotic solution containing penicillin $\mathrm{G}\left(100 \mu \mathrm{g} \mathrm{ml}^{-1}\right)$, streptomycin $\left(100 \mu \mathrm{g} \mathrm{ml}^{-1}\right)$ and amphotericin $\left(3 \mathrm{\mu g} \mathrm{ml}^{-1}\right)$. These cells were routinely grown in $25 \mathrm{~cm}^{2}$ tissue culture flask with $37^{\circ} \mathrm{C}$ in an atmosphere of $5 \% \mathrm{CO}_{2}$ with $90 \%$ relative humidity. For different experiments, cells were sub-cultured in 6-well plate till confluency. Cells of 20-40 passage numbers were used throughout the experiments.

\subsection{Bacterial strains and culture conditions}


An indigenous probiotic L. rhamnosus (LR:MTCC-5897) used under present investigation was previously isolated from household curd and characterized for probiotic attributes (Sharma et al. 2014). For this study, bacterial culture was activated in sterile de Man, Rogosa and Sharpe (MRS) broth (Hi-Media, Mumbai, Maharashtra, India) for $18 \mathrm{~h}$ under aerobic incubation at $37^{\circ} \mathrm{C}$ before use. Next day, activated culture was used to harvest bacterial pellets by centrifugation at $2000 \mathrm{xg}$ for $10 \mathrm{~min}$, followed by washing with phosphate buffered saline (PBS, pH-7.4). For in vitro treatments, bacterial pellets were resuspended in antibiotic free DMEM media to obtain $10^{9}$ colony forming unit (CFU) $\mathrm{ml}^{-1}$. The number of bacteria was determined by plate counting on MRS agar plates after aerobic incubation at $37^{\circ} \mathrm{C}$ for $24-$ $48 \mathrm{~h}$. This particular dose of L. rhamnosus was selected on the basis of previous investigation in which this probiotic was found safe in Caco-2 cells upto $24 \mathrm{~h}$ and displayed immunomodulatory effects in weanling mice (Bhat et al. 2019,b).

E. coli strain (ATCC:14948) was obtained from National Collection of Dairy Cultures (NCDC), NDRI, Karnal, Haryana (India). The culture was activated in nutrient broth under aerobic conditions for $18 \mathrm{~h}$ at $37^{\circ} \mathrm{C}$ and preceded as above for further work. For various experiments, the desired bacterial count $\left(1 \times 10^{8} \mathrm{CFU} \mathrm{ml^{- }}\right.$ $\left.{ }^{1}\right)$ was obtained by plate counting on eosin methylene blue (EMB) agar. Thereafter, the bacteria were resuspended in antibiotic free DMEM media to attain 100:1/well multiplicity of infection. This specific dose of $E$. coli was selected through preliminary study performed on barrier integrity in intestinal cells (Bhat et al. 2019, a).

\subsection{Stimulation of intestinal cells with bacteria}

Caco-2 cells with $1 \times 10^{5}$ cells $\mathrm{ml}^{-1}$ density were seeded in 6-well plate and after obtaining confluency, cells were treated with $L$. rhamnosus $\left(1 \times 10^{9} \mathrm{CFU} \mathrm{ml}{ }^{-1}\right)$ or $E$. coli $\left(1 \times 10^{8} \mathrm{CFU} \mathrm{ml} l^{-1}\right)$ for $3 \mathrm{~h}$ at $37^{\circ} \mathrm{C}$ in $5 \%$ $\mathrm{CO}_{2}$. For further experiments, Caco-2 cells were incubated with probiotic/ $E$. coli under three different challenge modes known as exclusion (Ex: pre-treatment), competition (Com) and displacement (Dis: posttreatment) respectively. In exclusion assay, Caco-2 cells were incubated with probiotic L. rhamnosus for 3 $\mathrm{h}$, then media was removed and cells were washed with PBS followed by $3 \mathrm{~h}$ incubation with $E$. coli containing DMEM medium for inflammatory stimulation. In competition assay, Caco-2 cells were simultaneously incubated with $L$. rhamnosus and $E$. coli for $3 \mathrm{~h}$. While, during displacement assay, Caco2 cells were initially treated with $E$. coli containing medium which was then removed after $3 \mathrm{~h}$ of incubation and cells were washed with PBS. Later, these intestinal cells were incubated with $L$. rhamnosus for $3 \mathrm{~h}$. In all these experimental assays, Caco-2 cells grown in DMEM media acted as a negative control. All sets of experiments were carried out in triplicate. The treated cells were washed with ice-cold PBS twice and used for RNA extraction and western blotting.

\subsection{RNA isolation and relative expression of genes associated with immune response}

Total RNA was isolated from Caco-2 cells following Trizol method as described in manufacturer protocol and further used for relative quantification of genes associated with immune response. Purity of the RNA 
was confirmed by determining O.D. at 260/280 ratio using microplate spectrophotometer (BioTek Instruments, Winooski, Vermont, USA). RNA integrity was confirmed on $1.5 \%$ agarose gel through electrophoresis. Total RNA $(1 \mu \mathrm{g})$ was reverse transcribed to cDNA using a reverse transcription kit (Thermo Fisher Scientific, Waltham, Massachusetts, USA) following user manual. The prepared cDNA was stored in $-20^{\circ} \mathrm{C}$ until used further. Quantitative real-time PCR (qRT) analysis, reactions were conducted to determine the relative gene expression by using ABI-fast 7500 thermocycler system (Applied Biosystems, California, USA). For mRNA expressions, qRT-PCR reactions were performed in $10 \mu \mathrm{l}$ reaction volume containing $1 \mu \mathrm{l}$ of test sample, $5 \mu \mathrm{L}$ of syber (Thermo scientific, USA), $0.5 \mu$ l of each primer and 3 $\mu l$ nuclease free water. Sequences of primers are shown in Table 1. GAPDH was used as a reference gene throughout the experiments. The thermal profile for reaction was: initial denaturation of $5 \mathrm{~min}$ at $94^{\circ} \mathrm{C}, 35$ cycles of denaturation $\left(94^{\circ} \mathrm{C}\right.$ for $\left.30 \mathrm{sec}\right)$, annealing $\left(60^{\circ} \mathrm{C}\right.$ for $\left.30 \mathrm{sec}\right)$ and extension $\left(60^{\circ} \mathrm{C}\right.$ for $\left.45 \mathrm{sec}\right)$ and final extension cycle at $60^{\circ} \mathrm{C}$ for $5 \mathrm{~min}$. After amplification, threshold (Ct) values of both control and treatment groups with reference genes (GAPDH) were used for calculating fold changes in respective target genes expression (Livak and Schmittgen 2001). 
Table 1

Sequence of primers along with their corresponding amplicon size for mRNA quantification immunity related genes using qRT-PCR

\begin{tabular}{|c|c|c|c|}
\hline Gene & Sequence of primer & Amplicon Length (bp) & Accession number \\
\hline \multicolumn{4}{|c|}{ Genes related to Interleukins } \\
\hline \multirow[t]{2}{*}{ IL-8 } & F 5'-GGTGCAGTTTTGCCAAGGAG-3' & 183 & NM_001354840.2 \\
\hline & R 5'-TTCCTTGGGGTCCAGACAGA-3' & & \\
\hline \multirow[t]{2}{*}{ IL-6 } & F 5'-GGCACTGGCAGAAAACAACC-3' & 85 & NM_001371096.1 \\
\hline & R 5'-GCAAGTCTCCTCATTGAATCC-3' & & \\
\hline \multirow[t]{2}{*}{ TNF-a } & F 5'-GGGACCTCTCTCTAATCAGC-3' & 103 & NM_000594.4 \\
\hline & R 5'-TCAGCTTGAGGGTTTGCTAC-3' & & \\
\hline \multirow[t]{2}{*}{ IL-23 } & F 5'-GTGGGACACATGGATCTAAGAGA-3' & 135 & NM_016584.3 \\
\hline & R 5'- CTGGTGGATCCTTTGCAAGC-3' & & \\
\hline \multicolumn{4}{|c|}{ Genes related to pathogen recognition receptor (PRR) } \\
\hline \multirow[t]{2}{*}{ TLR-2 } & F 5'-AGCACTGGACAATGCCACAT-3' & 113 & NM_001318796.2 \\
\hline & R 5'-ACCATTGCGGTCACAAGACA-3' & & \\
\hline \multirow[t]{2}{*}{ TLR-4 } & F 5'-CAAGAACCTGGACCTGAGCTT-3' & 200 & NM_138554.5 \\
\hline & R 5'-AAAAGGCTCCCAGGGCTAAA-3' & & \\
\hline \multirow[t]{2}{*}{ MyD-88 } & F 5'-CAGCGACATCCAGTTTGTGC-3' & 146 & NM_002468.5 \\
\hline & R 5'-GGCGGCACCTCTTTTCGAT-3' & & \\
\hline \multicolumn{4}{|c|}{ Genes related to NF-KB pathway } \\
\hline \multirow[t]{2}{*}{ NF-kB } & F 5'-ATGTGGGACCAGCAAAGGTT-3' & 134 & NM_001319226.2 \\
\hline & R 5'-CACCATGTCCTTGGGTCCAG-3' & & \\
\hline \multirow[t]{2}{*}{ SIGIRR } & F 5'-GGTATGTCAAGTGCCGTCTCAAC-3' & 120 & NM_001135054.2 \\
\hline & R 5'- AGCTGCGGCTTTAGGATGAAGT-3' & & \\
\hline
\end{tabular}

\subsection{Enzyme linked immunosorbent assay}

Cytokines secretions (TNF- $\alpha$, IL-10, TGF- $\beta$ and IFN- $Y$ ) were evaluated by enzyme linked immunosorbent assay (ELISA) (Biolegend Inc., San Diego, California, USA) in supernatants of Caco-2 cells according to manufacturer protocol. In brief, 96-well immune plates (Hi-media, Mumbai, Maharashtra, India) were coated with $100 \mu \mathrm{l}$ of capture antibody and incubated overnight at $4^{\circ} \mathrm{C}$. Next day after PBS/T washing, 
$200 \mu \mathrm{l}$ of blocking buffer was added to each well to avoid non-specific binding. Afterward, serially diluted respective standard cytokines or undiluted culture supernatant was used to determine the concentrations of interleukins. Then, $100 \mu \mathrm{l}_{\text {well }}{ }^{-1}$ of detection antibody of respective cytokines were added. Later, $100 \mu \mathrm{l}$ well $^{-1}$ HRP-conjugated avidin was added as detection enzyme. In final step, TMB substrate $(3,3,5,5$ tetramethyl diamine benzidine containing $0.03 \% \mathrm{H}_{2} \mathrm{O}_{2}$ ) was added for the development of colour and $2 \mathrm{~N}$ $\mathrm{H}_{2} \mathrm{SO}_{4}$ was used to stop the reaction. After that plate was read at $450 \mathrm{~nm}$ by using a microplate reader (BioTek Instruments, Winooski, Vermont, USA).

\subsection{Extraction of protein and determination of NF-KB nuclear translocation by western blotting}

Cytoplasmic and nuclear extracts of experimentally treated Caco-2 cells were collected by cell lysis using extraction reagents (Cytoplasmic nuclear extraction reagents Kit, Infobio, India) and protein concentrations were determined using Lowry method (Lowry 1951). After that, protein samples (30 $\mu \mathrm{g}$ well $^{-1}$ ) were separated on SDS-PAGE (Laemmli 1970) followed by blotting on PVDF membrane for detection of a specific protein. This membrane was blocked with $5 \%$ BSA (overnight) and incubated with primary antibody for $4 \mathrm{~h}$ at room temperature against NF-KB p-65 (1:100 dilution, Santa Cruz Biotech Inc, Dallas, Texas, USA), $\beta$-actin (1:1000 dilution, Sigma-Aldrich, St Louis, Missouri, USA) and Lamin (1:500 dilution, Santa Cruz Biotech Inc, Dallas, Texas, USA). The membrane was washed and incubated with horseradish peroxidase conjugated secondary antibody (Sigma-Aldrich, St Louis, Missouri, USA) for $2 \mathrm{~h}$ at room temperature. Signals were detected by using Dab Membrane Peroxidase tablets (Genetix, San Jose, California, USA).

\subsection{Statistical analysis}

Data were analysed using GraphPad Prism (Version 5.01) software. Experimental results are presented as means \pm S.E.M. Data were subjected to analysis of variance (ANOVA) and the Tukey test was used to separate the means $(p<0.05)$ which were considered statistically significant.

\section{Results}

\subsection{Modulation in intestinal cytokines}

In initial set of experiments, the immunomodulatory effect of probiotic L. rhamnosus on E. coli evoked inflammatory responses were analysed through measuring change in gene expressions of proinflammatory cytokines by qRT-PCR in Caco- 2 cells. Stimulation of Caco- 2 cells with $E$. coli for $3 \mathrm{~h}$ tremendously enhanced $(p \leq 0.01)$ the mRNA expressions of pro-inflammatory cytokines IL-8, TNF-a, and IL-23 by $8.12 \pm 1.74,8.75 \pm 2.18$ and $2.81 \pm 0.49$ folds as well as pleotropic cytokine IL- 6 by $3.81 \pm 0.44$ folds as compared to control cells (Fig. 1A-D). Interestingly, probiotic LR treatment individually for equivalent time did not bring much change in expressions of pro-inflammatory cytokines than control. Incubation of Caco-2 cells with $L$. rhamnosus during exclusion and completion of $E$. coli significantly ( $p$ $\leq 0.05$ ) reduced the expression of pro-inflammatory chemo-attractant IL-8 to $3.38 \pm 1.18$ and $4.19 \pm 0.24$ 
folds than E. coli ( $8.12 \pm 1.74$ folds) stimulated cells (Fig. 1A). Likewise, mRNA levels of pro-inflammatory marker TNF-a, decreased considerably $(\mathrm{p} \leq 0.01)$ during L.rhamnosus incubation in presence of E.coli irrespective of the mode of challenge (Fig. 1B). Pro-inflammatory cytokine IL-23 merely showed significantly $(p \leq 0.05)$ diminished mRNA transcription from intestinal cells during exclusion by probiotic LR than other modes of challenges with E. coli (Fig. 1C). On the other hand, no major alterations occurred in expression of IL-6 irrespective of the type of challenge between $E$. coli and probiotic bacteria during incubation with intestinal cells.

The results of actually released pro-inflammatory (TNF-a, IFN-Y) and regulatory cytokines (IL-10 and TGF$\beta)$ measured by ELISA are shown in Fig. 2. E. coli challenged Caco-2 cells showed significantly $(p \leq 0.05)$ higher release of inflammatory cytokines (TNF- $\alpha$ and IFN- $Y$ ) along with diminished secretions of antiinflammatory cytokine (IL-10) as compared to negative control cells. It was also observed that incubation of probiotic $L$. rhamnosus individually or during challenge with $E$. coli during exclusion, competition and displacement assays prevented inflammatory response by significantly $(p \leq 0.05)$ reducing the secretions of inflammatory cytokines (TNF-a, IFN-Y) than E. coli inflamed cells (Fig. 2A and B). On the other hand, probiotic $L$. rhamnosus treated intestinal cells showed much higher $(\mathrm{p} \leq 0.05)$ production of TGF- $\beta$ and IL-10 in comparison to E. coli inflamed cells (Fig. 2C and D). Besides, E. coli exclusion by L. rhamnosus significantly $(p \leq 0.05)$ enhanced the release of IL-10 and TGF- $\beta$ from intestinal cells, though assays based variations were observed during competition and displacement. Thus, it is clearly depicted that probiotic $L$. rhamnosus has an inhibitory effect on inflammatory milieu induced by $E$. coli in intestinal cells by suppressing pro-inflammatory cytokines and modulating anti-inflammatory cytokines more effectively during exclusion assay.

\subsection{Modulation in expression of Toll like receptors (TLRs)}

To get more insight in molecular events related to immunomodulation brought by L. rhamnosus, mRNA expressions of key pathogen recognition receptors (PRR's) were assessed in Caco-2 cells (Fig. 3). Stimulation of Caco-2 cells with E. coli or probiotic L. rhamnosus induced differential expression of these genes. mRNA transcription of TLR-4 was enhanced $(p \leq 0.05)$ to $2.83 \pm 0.13$ folds after exposure of $E$. coli than control cells (Fig. $3 \mathrm{~A}$ ) while it remained near to control levels on incubation with probiotic $L$. rhamnosus individually or suppressed it significantly $(p \leq 0.05)$ during respective exclusion and competition assays as compared to $E$. coli inflamed cells. On the other hand, exposure of probiotic $L$. rhamnosus noticeably ( $\mathrm{p} \leq 0.05)$ enhanced the TLR-2 expression by $2.42 \pm 0.42$ folds than $E$. coli infected cells. Similarly, probiotic $L$. rhamnosus caused significantly higher $(\mathrm{p} \leq 0.05)$ TLR-2 mRNA expression in intestinal cells than $E$. coli treated epithelial cells during exclusion as well as competition with inflammatory agent E. coli, (Fig. 3B). Though, displacement assays showed its transcriptional expression almost same to control or $E$. coli treated cells. mRNA expression of adaptor protein MyD-88, which regulates downstream signalling of all PRR's in intestinal cells showed statistically higher $(p<0.05)$ transcriptional activity in E. coli inflamed cells (Fig. 3C) without any major modulations in treatment groups. 


\subsection{Inhibition of NF-KB signalling in intestinal epithelial cells}

In present investigation, infection of Caco-2 cells with $E$. coli resulted in increased mRNA expression of NF-KB to $4.73 \pm 0.34$ folds $(p \leq 0.05$ ) than control. In contrast, probiotic $L$. rhamnosus exposure to intestinal cells kept mRNA transcription ( $1.84 \pm 0.14$ folds) close to control and significantly less $(p \leq$ 0.05 ) than $E$. coli treated cells. Exclusion and competition of $E$. coli with L. rhamnosus caused $3.05 \pm 0.62$ and $2.44 \pm 0.64$ folds of mRNA expression, respectively which differed insignificantly from control or $E$. coli treated intestinal epithelial cells (Fig. 4A). The inflammatory challenge of E. coli to epithelial cells suppressed $(\mathrm{p} \leq 0.05)$ transcription of single immunoglobulin IL-1R-related receptor (SIGIRR), a negative regulator of NF-KB, than control (Fig. 4B). While, L. rhamnosus incubation to intestinal epithelial cells individually or during various modes of challenge with $E$. coli resulted into significantly higher $(p \leq 0.05)$ transcription of SIGIRR than E. coli inflamed cells (Fig. 4B).

Figure $4 \mathrm{C}$ shows western blot analysis of nuclear translocation of NF-kB, p-65 subunit from cytoplasm which was essentially required for activation of inflammatory responses by secretion of various inflammatory cytokines. The nuclear translocation of $p-65$ subunit increased significantly $(p<0.05)$ in the cells infected with E. coli as compared to unstimulated negative control cells (Fig. 4d \& e). In opposition, cells treated with $L$. rhamnosus showed reduced nuclear translocation of $\mathrm{p}-65$. Likewise, pre-incubation of Caco-2 cells with $L$. rhamnosus before $E$. coli during exclusion assay also resulted in much less $(p \leq 0.05)$ translocation of this factor than E. coli inflamed cells (Fig. $4 \mathrm{~d} \& \mathrm{e}$ ), which was contrary to the observations made during competition or displacement assays.

\section{Discussion}

Intestinal epithelial cells, besides acting as a physical barrier, also play crucial role as immune modulator because epithelium is the site of interaction between microbes and host. Upon microbial pattern recognition by PRR's present at intestinal surface, epithelial cells initiate immune response through secretions of cytokines or chemokines. Probiotic stimulation modulates levels of cytokines through innate immune response mediated by pathogen recognition receptors (Brito et al. 2013), therefore evaluation of TLRs expression were utmost helpful in understanding the modulations of immune responses in intestinal cells. The mRNA expression of TLR-2 enhanced in the presence of $L$. rhamnosus was quite justifiable since Gram-positive bacteria have specific surface signature such as peptidoglycans, lipothechoic acid and lipopeptides which use TLR-2 signalling (Pinto et al. 2009). Probiotic utilized TLR-2 signalling for the release of IL-10 from regulatory T-cells to induce immune tolerance response (Konieczna et al. 2012). TLR-2 also played important role in induction of anti-microbial peptides which acted against the invasion of pathogens causing epithelial damage (Jia et al. 2019). Moreover, present study also confirmed that probiotic $L$. rhmanosus maintains immunotolerance through decreasing the expression of TLR-4 even in the presence of E. coli. Earlier probiotic L. jensenii TL2937 inhibited the increased TLR-4 levels induced by pathogenic E. coli or LPS infection in porcine epithelial cells (Shimazu et al. 2012). Likewise, treatment of intestinal cell with L. amylovorous or its supernatant reduced enterotoxigenic E. coli (ETEC) induced inflammatory response by decreasing TLR-4 regulated signalling 
(Finamore et al. 2014). Thus, these data clearly suggested that probiotic bacteria are exerting protective effect by differentially modulating the TLR signalling cascade and cytokines production that regulate immune response. Under current investigation, significant up-regulation of genes encoding proinflammatory markers IL-8, TNF-a, IFN-Y and IL-23 were observed in E. coli treated intestinal cells. These results are consistence with previous finding where increased expression of potent inflammatory markers (TNF- $\alpha$ and IL-8) were observed in response to E. coli (Dhanani and Bagchi 2013). Similarly, Ghadimi et al. (2012) reported enhanced expression of pro-inflammatory cytokine IL-23 in LPS stimulated intestinal cells. These increased syntheses of cytokines, induced inflammatory conditions, which could often be linked to the development of chronic inflammation and auto immune diseases causing serious health complications (Chen et al. 2018). Moreover, incubation of intestinal cells with probiotic L. rhamnosus, under present investigation, showed levels of pro-inflammatory cytokines similar to control which were quite lower than cells treated with $E$. coli. These observations are consistent with the earlier reports where no major change in the levels of pro-inflammatory cytokines with probiotic bifidobacteria or lactobacilli were observed (Bahrami et al. 2011). Probiotic strains are known to display their protective role against inflammatory stimulus either through down-regulation of pro-inflammatory cytokines expressions and upregulation of regulatory cytokines (Duary et al. 2014). This was also evident in the present investigation depending upon the mode of inflammatory challenge with $E$. coli wherein $L$. rhamnosus suppressed inflammatory responses by reducing pro-inflammatory (IL-8, TNF-a, IFN-Y) cytokines and simultaneously increased the release of anti-inflammatory cytokines (IL-10 and TGF- $\beta$ ). Similarly, previous findings with probiotic $L$. jensenii treatment before exposure with heat-killed enterotoxigenic $E$. coli reduced IL-8 expressions at transcriptional levels (Takanashi et al. 2013). Likewise, probiotic Bifidobacterium animalis $M B 5$ and $L$. rhamnosus $G G$ defended intestinal cells from pathogenic $E$. coli $\mathrm{K} 88$ induced inflammatory response by diminishing the production of inflammatory markers such as IL-8 and TNF-a (Roselli et al. 2006). On the same lines, probiotic L. acidophilus was able to counteract Salmonella typhimurium inflammatory responses by enhancing TGF- $\beta$ production in intestinal cells (Caco-2) (Haung et al. 2015). Although, under present investigation, post-treatment of probiotic $L$. rhamnosus during displacement assay was not found much effective in controlling inflammatory response but it clearly mitigated inflammatory responses and maintained intestinal homeostasis by achieving balance between pro and anti-inflammatory cytokines (Shadnoush et al. 2013) during exclusion and competition assays. For further insight into plausible mechanism of immunomodulation by probiotic $L$. rhamnosus in presence of E. coli induced inflammatory response, mRNA expression of NF-KB and its translocation from cytoplasm to nucleus were also explored. It was well established that regulated NF-KB dependent signalling is critical for efficient immune response, but prolonged activation contributes to generation of inflammatory diseases (Yan and Polk 2010). During present study, E. coli stimulation induced significant increase in mRNA expression of NF-KB in intestinal cells. On the other hand, $L$ rhamnosus suppressed expression of NF-KB at transcriptional level than E. coli treated cells. Likewise, probiotic L. acidophilus diminished Salmonella induced NF-KB transcriptional activity in intestinal epithelial cells (Huang et al. 2015). Similarly, co-stimulation of intestinal cells with probiotic Bifidobacterium lactis and inflammatory stimulus such as IL-1 $\beta$ and LPS also suppressed NF-KB activation (Kim et al. 2010). Inhibition of NF-KB signalling can be controlled through action of negative regulator such Tollip, SIGIRR, SOCS1 and IRAK-M 
which in turn help in maintaining homeostasis in intestinal cells (Finamore et al. 2014). These membrane-bound regulators modulate TLR signalling pathways by disrupting TLR and ligand interactions. Likewise, SIGIRR control NF-KB activation through interaction with IRAK and TRAF6 by inhibiting TLR signalling (Villena and Kitazawa 2014). Thus, reduced mRNA expression of SIGIRR in Caco-2 cells during E. coli infection in contrast to much enhanced expression with $L$. rhamnosus stimulation individually or during respective challenge assays, under present investigation, indicated inhibition of NF-KB signalling. These results are in consonance with previous finding which displayed better expression of SIGIRR in intestinal cells on stimulation with probiotic bifidobacteria (Tomosada et al. 2013). Similarly, in another study, probiotic L. delbrueckii inhibited E. coli 987P induced NF-кB pathways through enhancing TLR negative regulators in porcine intestinal cells (Wachi et al. 2014). Higher translocation of NF-kB p-65 subunit from cytosol to nucleus in intestinal cells by E. coli, observed under present investigation, also supported previous findings of Finamore et al. (2014). Impediment of $E$. coli induced inflammatory response by diminished translocation of $\mathrm{p}-65$ subunit from cytosol to nucleus by $L$. rhamnosus also supported previous results where pre-treatment of Caco-2BBe cells with $L$. rhamnosus GG diminished NF-KB activation induced by TNF-a (Donato et al. 2010). Thus, inhibition of NF-KB translocation during exclusion of E.coli with probiotic $L$. rhamnosus emerged as crucial factor for anti-inflammatory activity which in turn decreased the expression and release of pro-inflammatory cytokines and simultaneously substantiated the release of regulatory cytokines.

\section{Conclusion}

In summary, this study clearly provided direct insight into the mode of action of probiotic L. rhamnosus (LR:MTCC-5897) under inflammatory milieu induced by E. coli in intestinal cells. This potential probiotic strain displayed immunomodulatory and anti-inflammatory functions to varying extent in intestinal cells depending upon the type of $E$. coli challenge. However, differential expression of TLRs caused effective reduction in NF-kB p-65 nuclear translocation during exclusion of E.coli with L.rhamnosus. Thus immune homeostasis was achieved by reducing the expression of pro-inflammatory and enhancing the release of regulatory cytokines. Thus, it can be concluded that L. rhamnosus (LR:MTCC-5897) may be a potential candidate to produce nutraceuticals products for prevention of $E$. coli induced intestinal inflammation.

\section{Declarations}

\section{Acknowledgments}

The authors acknowledge ICAR-National Dairy Research Institute (NDRI) Karnal, for providing the laboratory facilities for execution of this work. We are also thankful to Department of Biotechnology, Ministry of Science and Technology, New Delhi for providing required funds.

\section{Funding}


The authors are highly indebted to the Department of Biotechnology, Ministry of Science and Technology, New Delhi for providing necessary funds. (BT/PR15109/PFN/20/1174/2015) required for the present work. The funding agency has no role in the design, analysis or writing of this article.

\section{Declarations}

The authors have no conflicts of interest to declare that are relevant to the content of this article.

\section{Author's Contribution}

Conceptualization : [Taruna Gupta], [Rajeev Kapila]; Methodology : [Taruna Gupta], [Harpreet Kaur] ; Formal analysis : [Taruna Gupta], [Rajeev Kapila],[Suman Kapila]; Investigation : [Taruna Gupta] ; Writingoriginal draft : [Taruna Gupta]; Writing - Review \& Editing [Harpreet Kaur], [Suman Kapila]; Software : [Taruna Gupta], [Harpreet Kaur]; Validation : [Taruna Gupta], [Rajeev Kapila]; Funding acquisition : [Rajeev Kapila]; Resources: [Rajeev Kapila], Supervision : [Rajeev Kapila]

\section{References}

1. Thursby E, Juge N (2017) Introduction to the human gut microbiota. Biochem J 474(11):1823-1836. https://doi.org/10.1042/BCJ20160510

2. Kawai T, Akira S (2009) The roles of TLRs, RLRs and NLRs in pathogen recognition. Int Immunol 21(4):317-337. https://doi.org/10.1093/intimm/dxp017

3. Oriach CS, Robertson RC, Stanton C, Cryan JF, Dinan TG (2016) Food for thought: The role of nutrition in the microbiota-gut-brain axis. Clin Nutr Exp 6:25-38. https://doi.org/10.1016/j.yclnex.2016.01.003

4. Belkaid Y, Hand TW (2014) Role of the microbiota in immunity and inflammation. Cell, 157(1), 121141

5. Lazar V, Ditu L, Pircalabioru G, Gheorghe I, Curutiu C, Holban AM, Chifiriuc CM (2018) Aspects of gut microbiota and immune system interactions in infectious diseases, immunopathology and cancer. Front. Immunol 9:1830. https://doi.org/10.3389/fimmu.2018.01830

6. Kittana H, Gomes-Neto JC, Heck K, Geis AL, Segura Muñoz RR, Cody LA, Schmaltz RJ, Bindels LB, Sinha R, Hostetter JM, Benson AK (2018) Commensal Escherichia coli strains can promote intestinal inflammation via differential interleukin-6 production. Front Immunol 9:2318

7. Bereswill S, Fischer A, Dunay IR, Kühl AA, Göbel UB, Liesenfeld O, Heimesaat MM (2013) Proinflammatory potential of Escherichia coli strains K12 and Nissle 1917 in a murine model of acute ileitis. Eur J Microbiol Immunol 3(2):126-34

8. Kim SC, Tonkonogy SL, Albright CA, Tsang J, Balish EJ, Braun J, Huycke MM, Sartor RB (2005) Variable phenotypes of enterocolitis in interleukin 10-deficient mice mono-associated with two different commensal bacteria. Gastroenterology 1;128(4):891-906 
9. Koli P, Sudan S, Fitzgerald D, Adhya S, Kar S (2011) Conversion of commensal Escherichiacoli K-12 to an invasive form via expression of a mutant histone-like protein. MBio 2(5)

10. Sharma R, Kapila R, Dass G, Kapila S (2014) Improvement in Th1/Th2 immune homeostasis, antioxidative status and resistance to pathogenic coli on consumption of probiotic Lactobacillus rhamnosus fermented milk in aging mice. Age 36(4):9686. https://doi.org/10.1007/s11357-0149686-4

11. Bhat MI, Sowmya K, Kapila S, Kapila R. Potential probiotic Lactobacillus rhamnosus (MTCC-5897) inhibits Escherichia coli impaired intestinal barrier function by modulating the host tight junction gene response (2019,a) Probiotics Antimicro 15:1-2. https://doi.org/10.1007/s12602-019-09608-8

12. Gronbach K, Flade I, Holst O, Lindner B, Ruscheweyh HJ, Wittmann A, Menz S, Schwiertz A, Adam P, Stecher B, Josenhans C (2014) Endotoxicity of lipopolysaccharide as a determinant of T-cell mediated colitis induction in mice. Gastroenterology 146(3):765-75

13. Galdeano CM, Cazorla SI, Dumit JML, Velez E, Perdigon G (2019) Beneficial effects of probiotic consumption on the immune system. Ann Nutr Metab 74(2):115-124. https://doi.org/10.1159/000496426

14. Bron PA, Kleerebezem M, Brummer RJ, Cani PD, Mercenier A, MacDonald TT, Garcia-Rodenas CL, Wells JM (2017) Can probiotics modulate human disease by impacting intestinal barrier function? $\mathrm{Br}$ J Nutr 117(1):93-107. https://doi.org/10.1017/S0007114516004037

15. Oh NS, Joung JY, Lee JY, Kim Y (2018) Probiotic and anti-inflammatory potential of Lactobacillusrhamnosus 4B15 and Lactobacillus gasseri 4M13 isolated from infant feces. PloS One 13. https://doi.org/10.1371/journal.pone.0192021

16. Groeger D, O'Mahony L, Murphy EF, Bourke JF, Dinan TG, Kiely B, Shanahan F, Quigley EM (2013) Bifidobacterium infantis 35624 modulates host inflammatory processes beyond the gut. Gut Microbes 4, 325-339. https://doi.org/10.4161/gmic.25487

17. Milajerdi A, Mousavi SM, Sadeghi A, Salari-Moghaddam A, Parohan M, Larijani B, Esmaillzadeh A (2019) The effect of probiotics on inflammatory biomarkers: A meta-analysis of randomized clinical trials. Eur J Nutr 1-17. https://doi.org/10.1007/s00394-019-01931-8

18. Horvath A, Leber B, Schmerboeck B, Tawdrous M, Zettel G, Hartl A, Madl T, Stryeck S, Fuchs D, Lemesch S, Douschan P (2016) Randomised clinical trial: the effects of a multispecies probiotic vs. placebo on innate immune function, bacterial translocation and gut permeability in patients with cirrhosis. Aliment Pharmacol Ther 44, 926-935. https://doi.org/10.1111/apt.13788

19. Chiu YH, Lu YC, Ou CC, Lin SL, Tsai CC, Huang CT, Lin MY (2013) Lactobacillusplantarum MYL26 induces endotoxin tolerance phenotype in Caco-2 cells. BMC Micro 13, doi.org/10.1186/1471-218013-190

20. Saliganti V, Kapila R, Sharma R, Kapila S (2015) Feeding probiotic Lactobacillus rhamnosus (MTCC 5897) fermented milk to suckling mothers alleviates ovalbumin-induced allergic sensitisation in mice offspring. Br J Nutr 114(8):1168-117. https://doi.org/10.1017/S000711451500286X 
21. Bhat MI, Singh VK, Sharma D, Kapila S, Kapila R $(2019, b)$ Adherence capability and safety assessment of an indigenous probiotic strain Lactobacillus rhamnosus MTCC-5897. Microb pathogen 130:120-130. https://doi.org/10.1016/j.micpath.2019.03.009

22. Livak KJ, Schmittgen TD (2001) Analysis of relative gene expression data using real-time quantitative PCR and the 2- $\triangle \triangle C T$ method. Methods $25,402-408$. https://doi.org/10.1006/meth.2001.1262

23. Lowry OH, Rosebrough NJ, Farr AL, Randall RJ (1951) Protein measurement with the Folin phenol reagent. J Biol Chem 193, 265-275. http://www.jbc.org/content/193/1/265

24. Laemmli UK (1970) SDS-page Laemmli method. Nature 227, 680-5

25. Bermudez-Brito M, Munoz-Quezada S, Gomez-Llorente C, Matencio E, Bernal MJ, Romero F, Gil A (2013) Cell-free culture supernatant of Bifidobacterium breve CNCM I-4035 decreases proinflammatory cytokines in human dendritic cells challenged with Salmonella typhi through TLR activation. PLoS One 8(3):59370. https://doi.org/10.1371/journal.pone.0059370.

26. Pinto MGV, Gomez MR, Seifert S, Watzl B, Holzapfel WH, Franz CM (2009) Lactobacilli stimulate the innate immune response and modulate the TLR expression of HT-29 intestinal epithelial cells in vitro. Int J Food Micro 133, 86-93. https://doi.org/10.1016/j.jfoodmicro.2009.05.013

27. Konieczna P, Groeger D, Ziegler M, Frei R, Ferstl R, Shanahan F, Quigley EM, Kiely B, Akdis CA, O'Mahony L (2012) Bifidobacterium infantis 35624 administration induces Foxp3 T regulatory cells in human peripheral blood: potential role for myeloid and plasmacytoid dendritic cells. Gut 61:354366. https://doi.org/10.1136/gutjnl-2011-300936

28. Jia Y, Si W, Hong Z, Qu M, Zhu N, Liu S, Li G (2019) Toll-like receptor 2-mediated induction of avian $\beta$ defensin 9 by Lactobacillus rhamnosus and its cellular components in chicken intestinal epithelial cells. Food Agr Immuno 30(1):398-417. https://doi.org/10.1080/09540105.2019.1593325

29. Shimazu T, Villena J, Tohno M, Fujie H, Hosoya S, Shimosato T, Aso H, Suda Y, Kawai Y, Saito T, Makino S (2012) Immunobiotic Lactobacillus jensenii elicits anti-inflammatory activity in porcine intestinal epithelial cells by modulating negative regulators of the Toll-like receptor signaling pathway. Infect Immune 80(1):276-288. https://doi.org/10.1128/IAI.05729-11

30. Finamore A, Roselli M, Imbinto A, Seeboth J, Oswald IP, Mengheri E (2014) Lactobacillus amylovorus inhibits the TLR4 inflammatory signaling triggered by enterotoxigenic Escherichia colivia modulation of the negative regulators and involvement of TLR2 in intestinal Caco-2 cells and pig explants. PLoS One 9(4):94891. https://doi.org/10.1371/journal.pone.0094891

31. Dhanani AS, Bagchi T (2013) Lactobacillus plantarum 2 prevents Escherichia coli adhesion to HT29 cells and also down- regulates enteropathogen induced tumor necrosis factor- $a$ and interleukin-8 expression. Microbiol Immunol 57(4):309-315. https://doi.org/10.1111/1348-0421.12038

32. Ghadimi D, Helwig U, Schrezenmeir J, Heller KJ, de Vrese M (2012) Epigenetic imprinting by commensal probiotics inhibits the IL- 23/IL- 17 axis in an in vitro model of the intestinal mucosal immune system. J Leukoc Biol 92(4):895-911. https://doi.org/10.1189/jlb.0611286 
33. Chen L, Deng H, Cui H, Fang J, Zuo Z, Deng J, Li Y, Wang X, Zhao L (2018) Inflammatory responses and inflammation-associated diseases in organs. Oncotarget 9, 7204

34. Bahrami B, Macfarlane S, Macfarlane GT (2011) Induction of cytokine formation by human intestinal bacteria in gut epithelial cell lines. J Appl Microbiol 110(1):353-363. https://doi.org/10.1111/j.13652672.2010.04889.x

35. Duary RK, Batish VK, Grover S (2014) Immunomodulatory activity of two potential probiotic strains in LPS-stimulated HT-29 cells. Genes \& Nutr 9(3):398. https://doi.org/10.1007/s12263-014-0398-2

36. Takanashi N, Tomosada Y, Villena J, Murata K, Takahashi T, Chiba E, Tohno M, Shimazu T, Aso H, Suda Y, Ikegami S (2013) Advanced application of bovine intestinal epithelial cell line for evaluating regulatory effect of lactobacilli against heat-killed enterotoxigenic Escherichia coli-mediated inflammation. BMC Microbiol 13(1):54. https://doi.org/10.1186/1471-2180-13-54

37. Roselli M, Finamore A, Britti MS, Mengheri E (2006) Probiotic bacteria Bifidobacterium animalis MB5 and Lactobacillus rhamnosus GG protect intestinal Caco-2 cells from the inflammation associated response induced by enterotoxigenic Escherichia coli $\mathrm{Br} \mathrm{J}$ Nutr 95(6):1177-1184. https://doi.org/10.1079/bjn20051681

38. Huang IF, Lin IC, Liu PF, Cheng MF, Liu YC, Hsieh YD, Chen JJ, Chen CL, Chang HW, Shu CW (2015) Lactobacillus acidophilus attenuates Salmonella-induced intestinal inflammation via TGF- $\beta$ signaling. BMC Microbiol 15(1):203. https://doi.org/10.1186/s12866-015-0546-x

39. Shadnoush M, Hosseini RS, Mehrabi Y, Delpisheh A, Alipoor E, Faghfoori Z, Mohammadpour N, Moghadam JZ (2013) Probiotic yogurt affects pro-and anti-inflammatory factors in patients with inflammatory bowel disease. IJPR 12, 929

40. Yan F, Polk DB (2010) Disruption of NF-KB signalling by ancient microbial molecules: novel therapies of the future. BMJ 421-426. https://doi.org/10.1136/gut.2009.179614

41. Kim SW, Kim HM, Yang KM, Kim SA, Kim SK, An MJ, Park JJ, Lee SK, Kim TI, Kim WH, Cheon JH (2010) Bifidobacterium lactis inhibits NF-KB in intestinal epithelial cells and prevents acute colitis and colitis-associated colon cancer in mice. Inflamm Bowel Dis 16(9),1514-1525

42. Villena J, Kitazawa H (2014) Modulation of intestinal TLR4-inflammatory signaling pathways by probiotic microorganisms: lessons learned from Lactobacillus jensenii Front Immunol 4:512. https://doi.org/10.3389/fimmu.2013.00512

43. Tomosada Y, Villena J, Murata K, Chiba E, Shimazu T, Aso H, Iwabuchi N, Xiao JZ, Saito T, Kitazawa $H$ (2013) Immunoregulatory effect of bifidobacteria strains in porcine intestinal epithelial cells through modulation of ubiquitin-editing enzyme A20 expression. PLoS One 8(3):59259. https://doi.org/10.1371/journal.pone.0059259

44. Wachi S, Kanmani P, Tomosada Y, Kobayashi H, Yuri T, Egusa S, Shimazu T, Suda Y, Aso H, Sugawara M, Saito T (2014) Lactobacillus delbrueckii TUA $4408 \mathrm{~L}$ and its extracellular polysaccharides attenuate enterotoxigenic Escherichia coli- induced inflammatory response in porcine intestinal epitheliocytes via Toll- like receptor- 2 and 4. Mol Nutr Food Res 58 (10):2080-2093. https://doi.org/10.1002/mnfr.201400218 
45. Donato KA, Gareau MG, Wang YJJ, Sherman PM (2010) Lactobacillus rhamnosus GG attenuates interferon- $y$ and tumour necrosis factor-a-induced barrier dysfunction and pro-inflammatory signalling. Microbiol 156(11):3288-3297. https://doi.org/10.1099/mic.0.040139

\section{Figures}

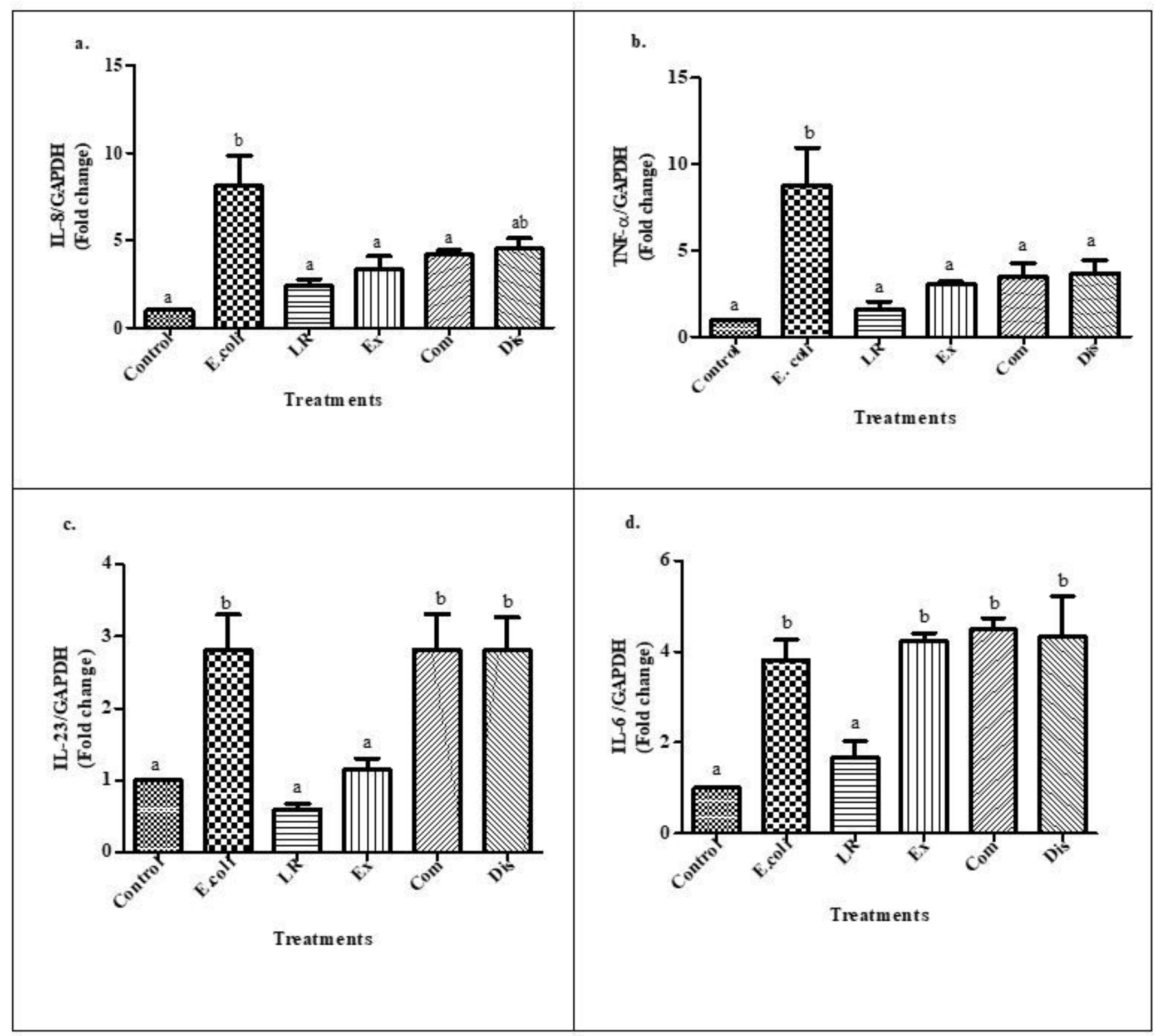

Figure 1

Transcriptional modulations of genes associated with immune signals (A: IL-8; B: TNF-a; C: IL-23; D: IL-6) during challenge with $\mathrm{E}$. coli in the presence of probiotic $\mathrm{L}$. rhamnosus. Values are expressed as means \pm SEM $(n=3)$. Means with different alphabets indicate significant difference $(p<0.05)$ 


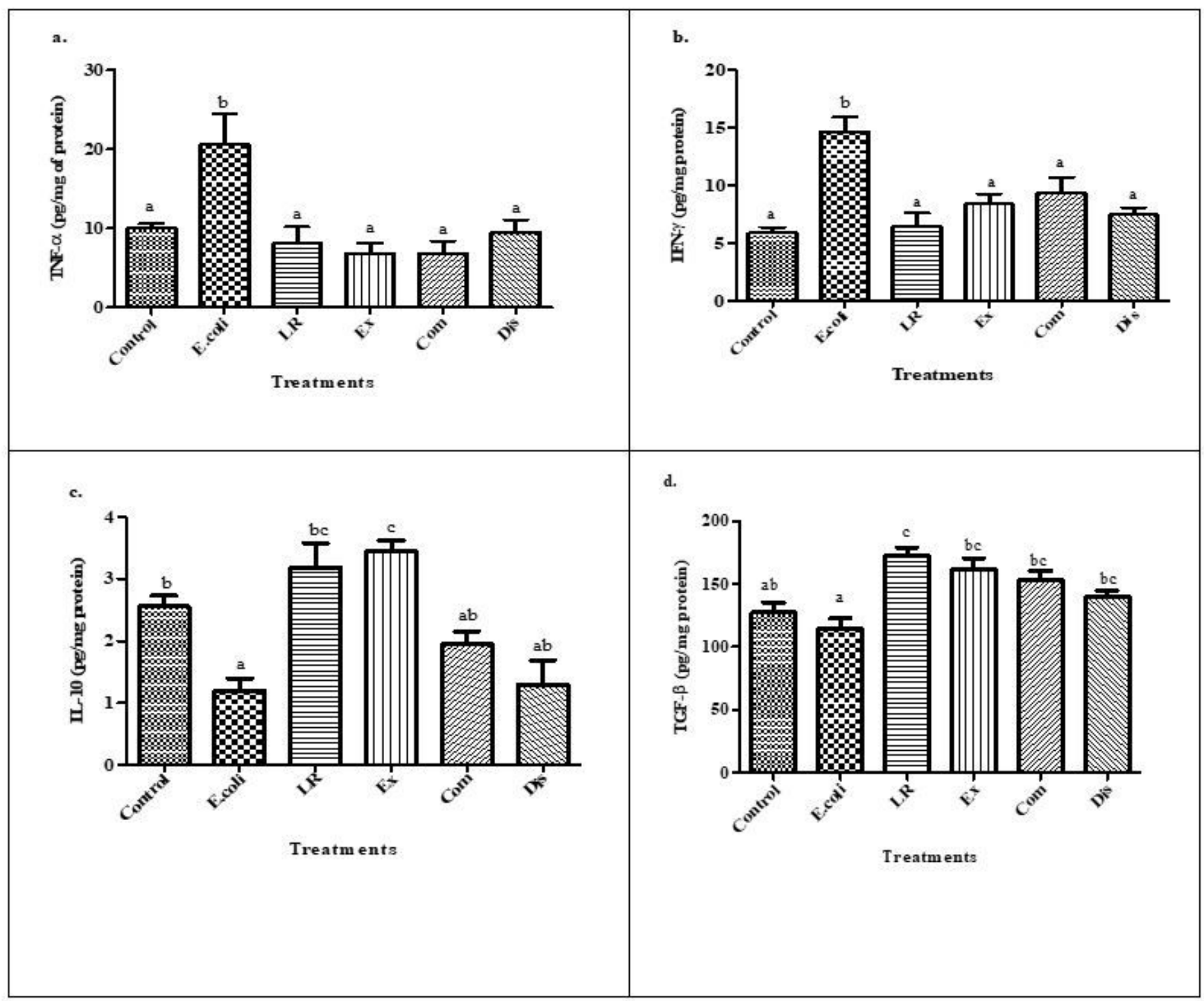

Figure 2

Release of interleukins (A: TNF-a; B: IFN- - ; C: IL-10; D: TGF- $\beta$ ) as immune signals by intestinal epithelial cells during challenge with $\mathrm{E}$. coli in the presence of probiotic L. rhamnosus. Values are expressed as means $\pm \operatorname{SEM}(n=3)$. Means with different alphabets indicate significant difference $(p<0.05)$ 


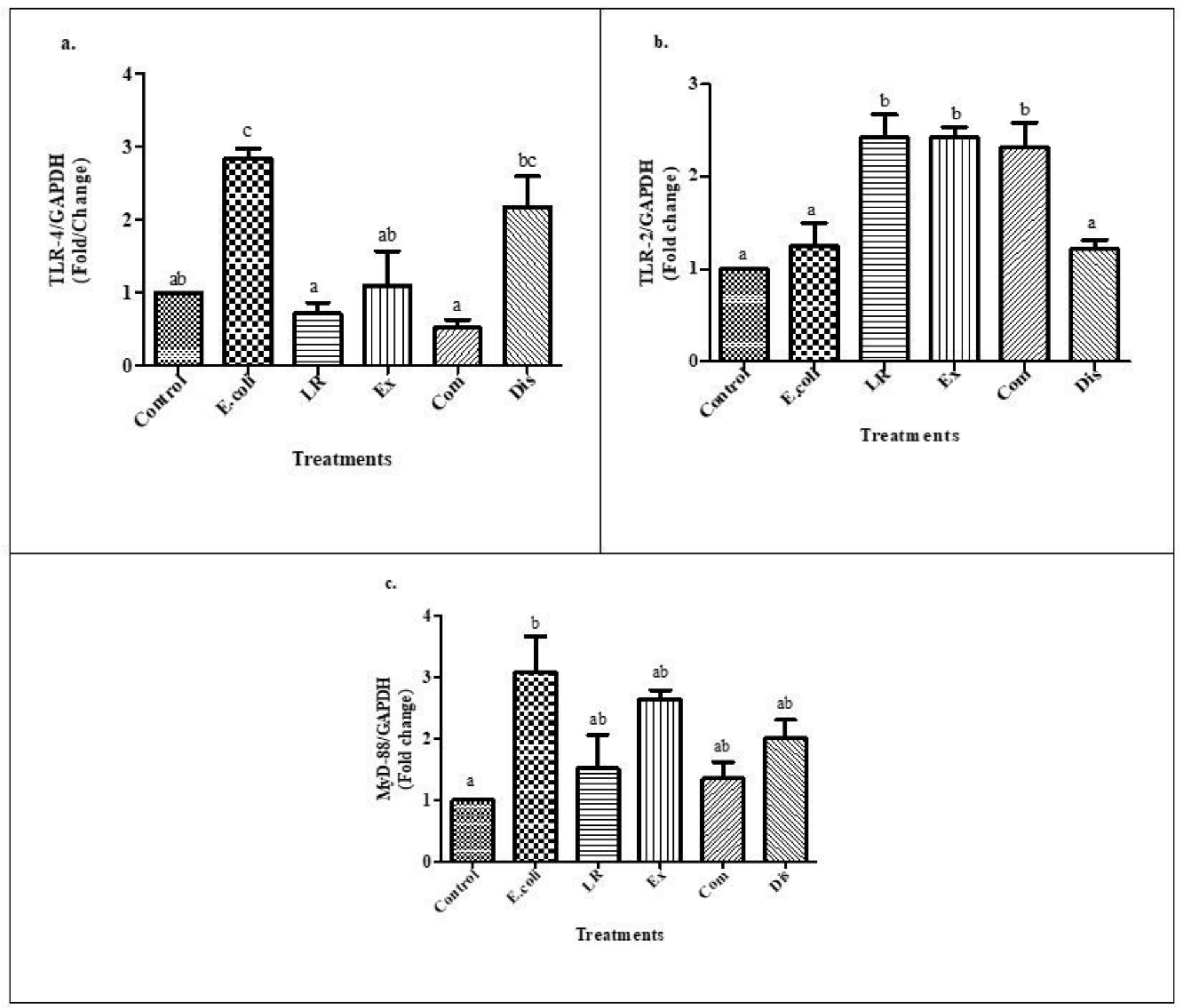

Figure 3

Transcriptional modulations of pathogen recognition receptor genes (A: TLR-2; B: TLR-4) and adaptor protein (C: MyD-88) during challenge with $\mathrm{E}$. coli in the presence of probiotic L. rhamnosus. Values are expressed as means \pm SEM $(n=3)$. Means with different alphabets indicate significant difference $(p<$ $0.05)$ 


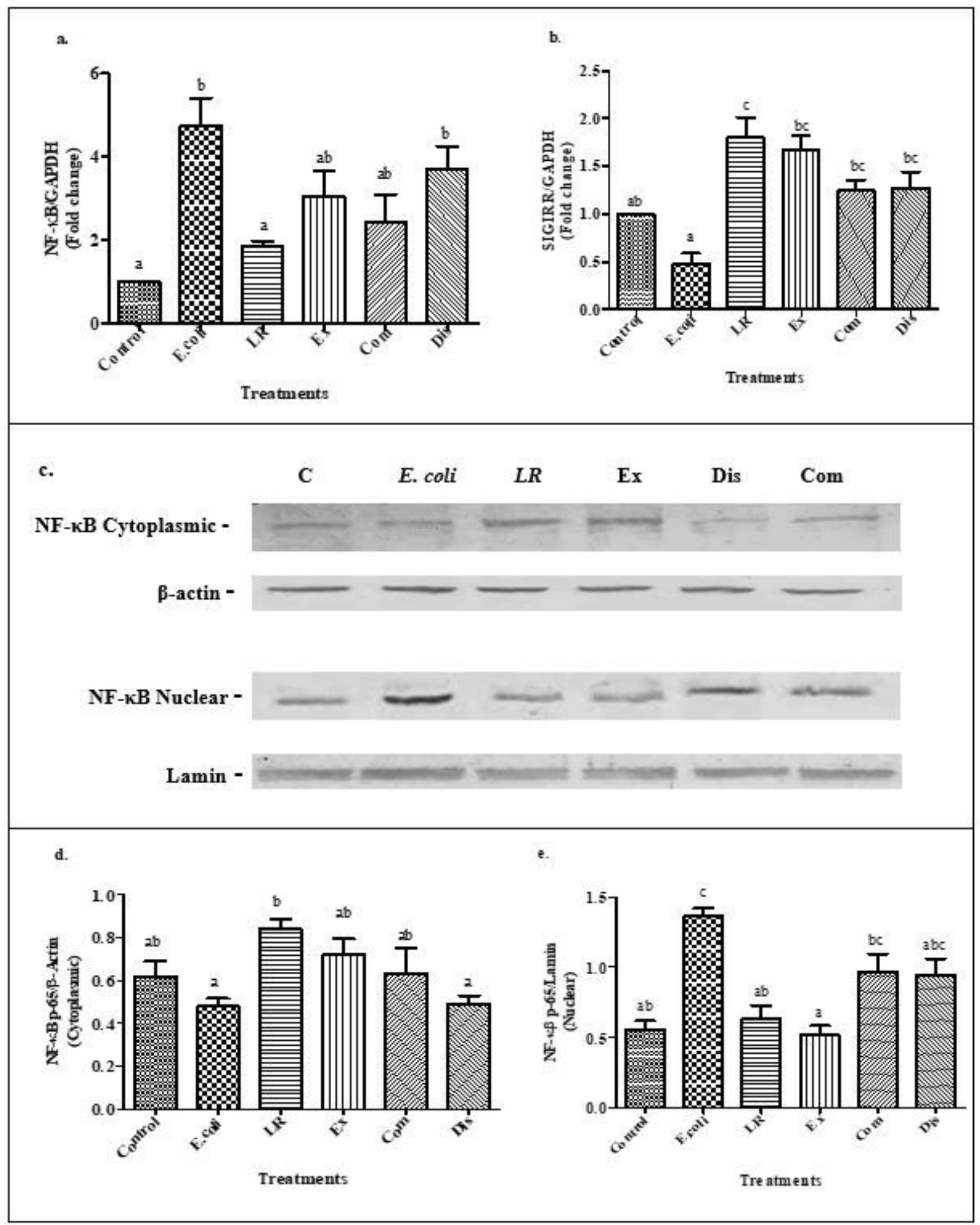

Figure 4

Effect of E. coli challenge on NF-KB master regulator of inflammation in the presence of probiotic $L$. rhamnosus. A: Modulation in transcriptional expression of NF-KB; B: SIGIRR genes; C: Translocation of NF-KB ( $p-65)$ from cytosol to nucleus by western blotting; D: Relative density of cytoplasmic NF-KB ( $p-65)$ bands; E: Relative density of nuclear NF-kB ( $p-65$ bands). Values are expressed as means \pm SEM $(n=3)$. 
Means with different alphabets indicate significant difference $(p<0.05)$ LR: Lactobacillus rhamnosus, Ex: Exclusion, Com: Competition, Dis: Displacement 